\title{
The comparative thermodynamic analysis of compressor's energetic performance
}

\author{
Cristian Eparu*, Sorin Neacşu, Adrian Neacşa, Alina Prundurel \\ Petroleum - Gas University of Ploiesti, 39 Bucharest Blvd., Ploiesti 100680, Romania
}

Corresponding Author Email: cristian.eparu@gmail.com

https://doi.org/10.18280/mmep.060120

Received: 14 September 2018

Accepted: 5 March 2019

\section{Keywords:}

compressor, energy, gas, performance, thermodynamic

\begin{abstract}
The screw compressors have been growing massively in popularity due to the high level of efficiency, the small gauge dimensions and the big time-intervals between the maintenances. Oil injection screw compressors are capable of reaching high performance by realizing major compression reports in one single stage, and, by upgrading the splitting technology/ using a better oil, the areas of applicability are continuously expanding. The paper is intended to analyze different types of compressors used for natural gases' compression, to put under observation the evolution tendencies when it comes to the output parameters and implementation technologies, all of this in the context of the development strategy of the national natural gas transmission system. An algorithm will be presented throughout the paper, as well as thermodynamic calculation methodologies to highlight the performance of the analyzed machines and benchmarking the energy performance of the oil injection screw compressor compared to other similar machines. For all of the above to be achievable an engineering algorithm has been developed and materialized in a programming environment known as Visual Studio/C\#, which allows easily modeling thermodynamic processes and calculating the parameters of the analyzed machines.
\end{abstract}

\section{INTRODUCTION}

The evolution of parameters of gas extraction stations over time means modifying the work parameters - decreasing debits, suction pressures, etc. - fact which negatively influences the functioning of the compressing equipment. Those gears need to be upgraded for being able to adapt to the work parameters variation, or need to be redesigned. There are gas extraction stations which had a major parameter variation, thus decreasing the pressure in the deposit. Old gas extraction stations, designed by the initial parameters of the location, end up not keeping up with the new parameters, resulting in either shutting down the station or upgrading it by utilizing equipment compatible with the modified parameters [1].

The Romanian developing strategy regarding raising the levels of security when it comes to electric energy supplying and limitation on energetic resources import, in a fast-growing economy, includes, among others, implementing a sustained energy conservation policy by maximizing its recovery from all available energy sources.

Having given the fact that the developing strategy of Transgaz (company responsible of gas transportation in Romania), includes pressure rising in transportation pipes, in the first stage at 45 bar, the compressor-producing companies responded to this trend so that 45 bar pressure screw compressors were made.

The screw compressor is part of the volumetric compressors category because the pressure increase is achieved by lowering the workspace volume. The major advantage of these types of compressors is that the compression process is continuous, the machine has no valves and is less sensitive to gas quality $[2,3$, 4]. The screw compressor consists of two helical rotors rotating inside a housing. One of the helical rotors is driven by a reducer and the other is free, being trained by contact with the first rotor $[1,5]$.

In Figure 1, one can observe the variation of the working volume for the mass of gas that periodically passes the compressor.
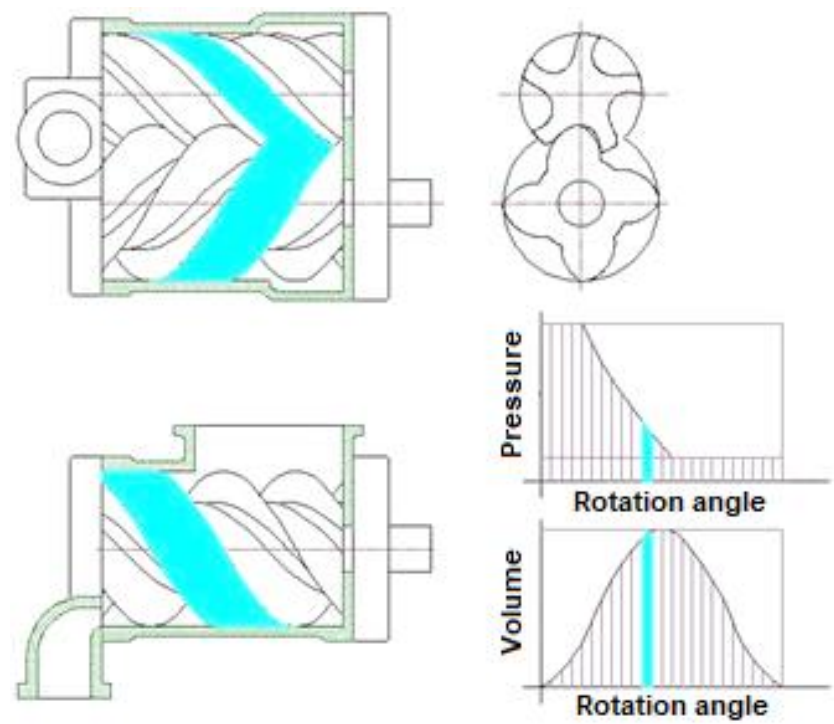

Figure 1. Presentation of the working volume variation for the mass of gas passing through the compressor

The performance of the screw compressors is determined by the mass flow through it. Let's have $m_{v}$ being the gas mass trapped in the working volume that is formed between two 
successive helical profiles. The flow flowing through the compressor is given by the Equation (1):

$\dot{m}=m_{v} Z_{1} \frac{n}{60}$

The volume of gas supplied by the compressor can be expressed in terms of input conditions for which the gas' density is $\rho_{0}\left(p_{0}, T_{0}\right)$ or the normal state function $\rho_{N}\left(p_{N}, T_{N}\right)$.

$\dot{V}=\frac{\dot{m}}{\rho_{0}} \cdot 60\left[\mathrm{~m}^{3} / \mathrm{min}\right]$

$\dot{V}_{N}=\frac{\dot{m}}{\rho_{N}} \cdot 60\left[\mathrm{~m}^{3} / \mathrm{min}\right]$

The maximum theoretical flow calculated from geometric considerations is presented in Equation (4)

$\dot{m}_{t}=\frac{\left(A_{1 N}+A_{2 N}\right) L n Z_{1} \rho}{60}$

Volumetric efficiency is defined by the ratio between the actual gas flow through the compressor and the theoretical flow, Equation (5).

$\eta_{V}=\frac{\dot{m}}{\dot{m}_{t}}$

If we use $L$ for the indicated mechanical work experimentally deduced from the $p v$ diagram for a single working volume, the indicated power required to drive the compressor shall be calculated with Equation (6):

$P_{\text {ind }}=\frac{L_{i} n Z_{1}}{60}$

The technological advances made in the construction of screw compressors have made them successfully used to replace piston compressors in the oil industry. Screw compressors are also used to make heat pumps and refrigeration units.

\section{THE THERMODYNAMIC MODEL OF THE PROCESS FROM A SCREW COMPRESSOR}

From a thermodynamic point of view, the screw compressor is considered to be an open system because, during the operation, during the working process, a mass change with the external environment is made [7]. Figure 2 shows the flows flowing through the compressor schematically. Inside the machine there is gas entering and possibly pulverized oil and outcomes as compressed gas and the oil introduced.

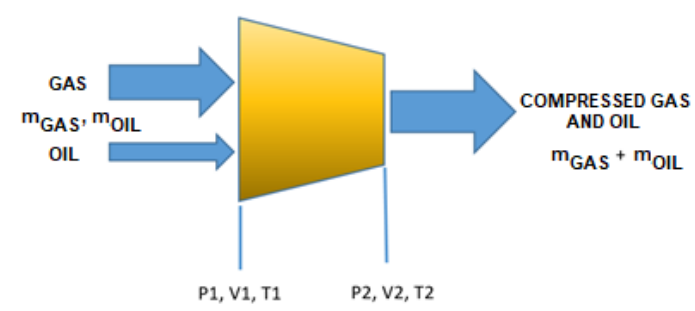

Figure 2. Flow diagram for a screw compressor

In order to study the process, a specialized software was developed in the Visual Studio/C \# programming environment that allows modeling of the thermodynamic processes and calculating the parameters of the analyzed machines. Figure 3 shows a part of the program interface.

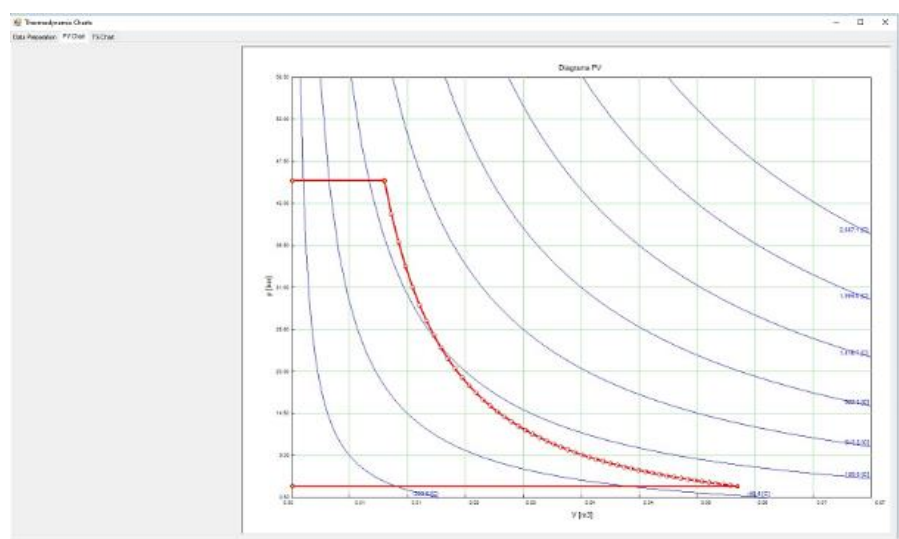

(a) Thermodynamic Cycle

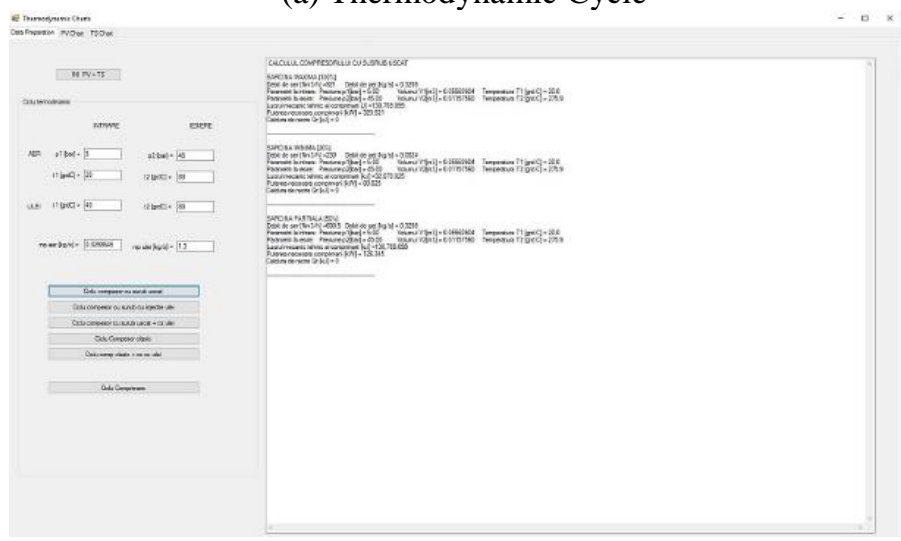

(b) parameter's calculation of the analyzed machines

Figure 3. Program computing interface

For modeling the thermodynamic processes in a screw compressor, a thermodynamic cycle consisting of an adiabatic modeling gas compression was chosen [6], process 1 - 2 of Figure 3, a 2 - 3 sample shaping the compressed gas discharge process and a second isobar $3-1$ that model the gas intake in the car. Since the rotary compressor does not have a damaging volume like the piston compressor, the entire amount of compressed gas is evacuated. For this reason, the cycle is completed with isochore $3-4$. The thermodynamic cycle of the screw compressor is shown in figure 3.

The assumptions used in the analysis are as follows:

$>\quad$ The thermodynamic cycle evolves gases considered perfect gases, which respect Clapeyron's state equation;

$>$ Status transformations that shape the compression process are considered irreversible, irreversibility being characterized by isentropic yield [8];

$>$ Status transformations that characterize intake and evacuation processes are considered reversible [9].

\section{PRESENTATION OF RESULTS AND PERFORMANCE ANALYSIS OF COMPRESSORS}

\subsection{Comparison between oil-free screw compressor and oil injection screw compressor}

Because the oil injected into the compressor besides the mechanical effects also has a significant thermodynamic effect by cooling the compressed gas, and in practice oil-free screw 
compressors are also used to perform the thermodynamic modeling of an oil-free screw compressor to have a comparison to the oil injection. For this case, the hypothesis that the compression process is an irreversible adiabatic process was used [3]. The calculations were performed for the maximum load $(100 \%)$, the minimum load $(20 \%)$ and the average load $(60 \%)$. The variation of the load was achieved by the corresponding change in the input flow.

Because the injected oil significantly alters the compression process for computing this type of compressor, the following parameters were considered:

$>$ Input $\mathrm{p}_{1}=5 \mathrm{bar} ; \mathrm{t}_{1}=20^{\circ} \mathrm{C}$;

$>$ Output $\mathrm{p}_{2}=45$ bar; $\mathrm{t}_{2}=80^{\circ} \mathrm{C}$.

The parameters are similar to those obtained experimentally on the stand for similar machines.

The comparative results are shown in Figure 4 and in Table 1. In Figure 4, the oil-free compressor cycle is shown in green and square markings, and the oil injection compressor cycle is shown in red and circle marking. It is noted that the mechanical work consumed for compressing the gas is lower in the case of the oil-injected compressor than the dry compressor.

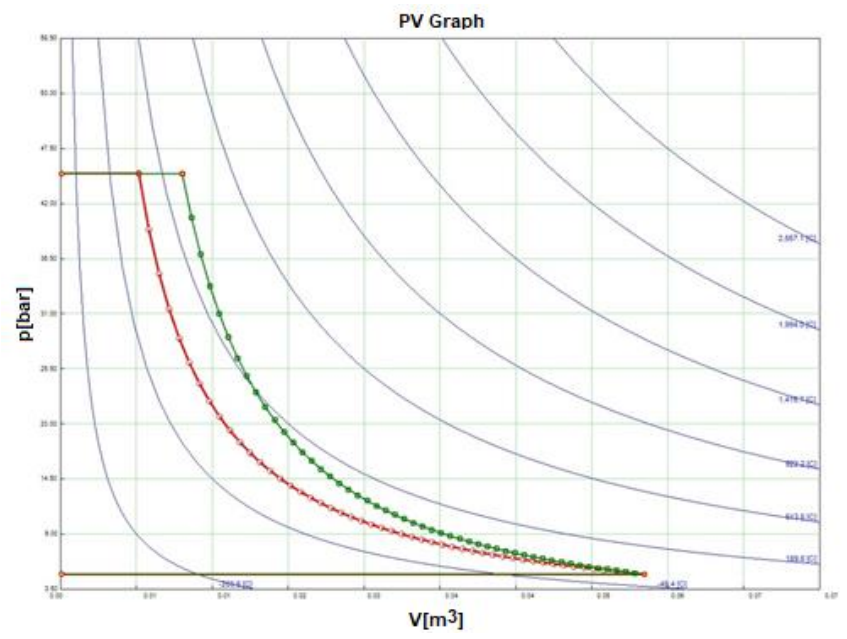

Figure 4. Comparison between the performance of the oilinjected and oil-injected compressor

Table 1. Comparative presentation between the oil-free screw compressor and oil injection screw compressor

\begin{tabular}{|c|c|c|c|c|}
\hline \multirow{2}{*}{$\begin{array}{c}\text { Load } \\
{[\%]}\end{array}$} & $\begin{array}{c}\text { Compressor without oil } \\
\text { injection }\end{array}$ & \multicolumn{2}{|c|}{$\begin{array}{c}\text { Compressor with oil } \\
\text { injection }\end{array}$} \\
\cline { 2 - 5 } & Power [kW] & $\mathbf{T}_{\mathbf{2}}\left[{ }^{\mathbf{0}} \mathbf{C}\right]$ & Power [kW] & $\mathbf{T}_{\mathbf{2}}\left[{ }^{\mathbf{}} \mathbf{C}\right]$ \\
\hline 100 & 323.52 & 275.9 & 255.59 & 80 \\
\hline 20 & 80.82 & 275.9 & 63.85 & 80 \\
\hline 60 & 126.34 & 275.9 & 99.81 & 80 \\
\hline
\end{tabular}

It is easy to see that in the case of an oil-injected screw compressor, the compression forces required for all the loads being analyzed are significantly lower than for the dry compressor. Another advantage of the oil-injected screw compressor is the low discharge temperature of compressed gas $80{ }^{\circ} \mathrm{C}$ to $275.9{ }^{\circ} \mathrm{C}$.

\subsection{Comparison between the oil injection screw compressor and the piston compressor}

To make a good comparison, the most used compressor, the piston compressor, was chosen. Figure 5 shows schematically the piston volumetric compressor.

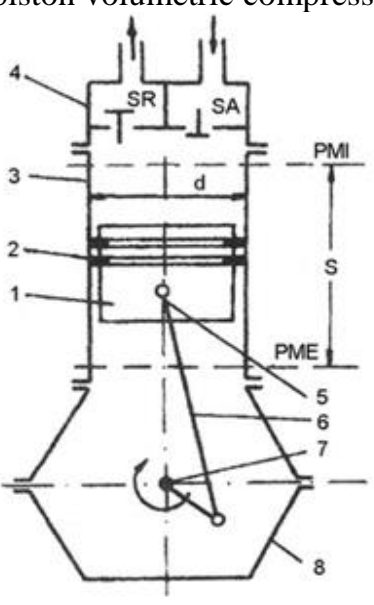

1-The piston

2-The segments

3-Block of cylinders

4-Cylinder head

5-The axle of the piston

6-Rod

7-Crankshaft

8-Compress or casing

SR - discharge valve

$\mathrm{SA}$ - Inlet valve

d- cylinder diameter

s- piston stroke

PMI - the dead inner point

PME- the dead outter point
Figure 5. Piston volumetric compressor

Its energy performance has been determined assuming it works with the same load as the oil injection screw compressor, i.e. it compresses the same flow under the same conditions.

The comparative results between the piston compressor and the oil injection screw compressor are shown in Table 2 and in the diagram in Figure 6.

It can be seen that also with respect to this type of compressor, the oil injection screw compressor is more economical for all loading regimes, and also the discharge temperature is low.

Table 2. Comparative presentation between the piston compressor and the oil injection screw compressor

\begin{tabular}{|c|c|c|c|c|}
\hline \multirow{2}{*}{$\begin{array}{c}\text { Load } \\
{[\%]}\end{array}$} & $\begin{array}{c}\text { Compressor without oil } \\
\text { injection }\end{array}$ & \multicolumn{2}{c|}{$\begin{array}{c}\text { Compressor with oil } \\
\text { injection }\end{array}$} \\
\cline { 2 - 5 } & Power [kW] & $\mathbf{T}_{\mathbf{2}}\left[{ }^{\mathbf{0}} \mathbf{C}\right]$ & Power [kW] & $\mathbf{T}_{\mathbf{2}}\left[{ }^{\mathbf{}} \mathbf{C} \mathbf{]}\right.$ \\
\hline 100 & 334.26 & 275.9 & 255.59 & 80 \\
\hline 20 & 83.51 & 275.9 & 63.85 & 80 \\
\hline 60 & 208.89 & 275.9 & 99.81 & 80 \\
\hline
\end{tabular}

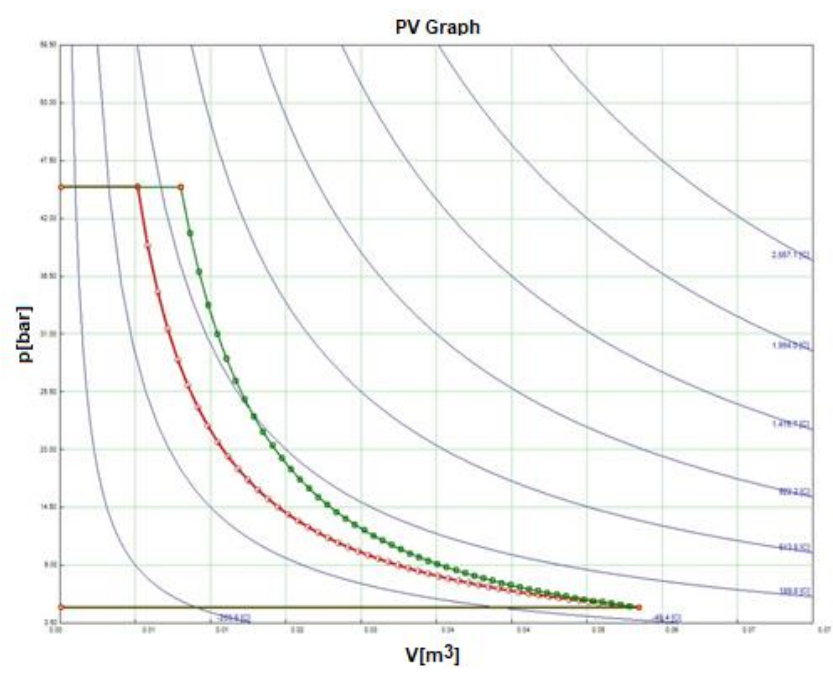

Figure 6. Comparison between piston compressor (green, square) and oil injection screw compressor (red, circles)

\section{CONCLUSIONS}

Due to the high flexibility and maintainability, oil-injected 
screw compressors can be used both in oil/gas extraction stations, offshore stations due to relatively small dimensions, relatively low weight and low operating noise, petrochemical industry or applications industrial piping, gas pumping in pipelines or storage tanks, the gas booster system, marine platforms, but also the replacement of old compressors already in the locations of the beneficiaries.

An algorithm materialized in a modern software product specializing in Visual Studio/C \# programming environment has been developed to perform computational performance analysis to calculate the performance of the analyzed machines and to represent the thermodynamic cycles in professional diagrams.

Thermodynamic cycles for oil-free screw compressor, oil injection screw compressor, and piston volumetric compressor were built.

Comparative analyzes were made on the basis of the results obtained assuming that all the analyzed machines compressed the same amount of gas, the initial state and hypotheses being similar for all analyzes.

The results showed the superiority of the oil injection screw compressor. Injected oil in addition to reducing friction has an important role in the thermodynamic process by cooling the compressed gas during the compression process. This makes the operation of the oil injection screw compressor very close to the behavior of an isothermal compressor. We recall that the ideal compression process, which is done with minimal energy consumption, is the isothermal process.

\section{ACKNOWLEDGMENT}

This research was part of a project financed by Executive Unit for Financing Higher Education, Research, Development and Innovation (UEFISCDI) within Bridge Grant (Knowledge Transfer to the Enterprise).

\section{REFERENCES}

[1] Van Wylen G, Sonntag R, Borgnakke C. (1994). Fundamentals of Classical Thermodynamics, Jon Wiley \& Sons New York, USA.

[2] Neacșu S. (2009). Termotehnică și mașini termice, Editura Printeh, București, Romania.

[3] Oroveanu T, Trifan C, Albulescu M. (1991). Sur le taux optimal de compression pour le gazoducs, Buletin I.P.G. Ploieşti XLIII(2).
[4] Radcenco V. (1994). Termodinamica generalizata, Editura Tehnica, București, Romania.

[5] Ştefănescu M, Silivestru V, Liviu A, Neacşu S, Florea I, Eparu C. (2008). Mentenanța turbomotoarelor, Editura Universității Petrol-Gaze din Ploieşti, Ploieşti, Romania.

[6] Neacsu S. (2009). Comprimarea şi lichefierea gazelor, Editura Romconvert, Ploiești, Romania.

[7] Stosic N, Smith I, Kovacevic A. (2005). Screw Compressors Mathematical Modeling and Performace Calculation, Springer VerlagBerlin Heidelberg.

[8] Giannetti N, Rocchetti A, Saito K. (2016). Thermodynamic optimization of three-thermal irreversible systems. International Journal of Heat and Technology 34: S83-S90. http://dx.doi.org/10.18280/ijht.34S110

[9] Incropera FP, DeWitt DP. (1990). Fundamentals of Heat and Mass Transfer. John Wiley \& Sons, New York, USA.

\section{NOMENCLATURE}

$\begin{array}{ll}\dot{m} & \begin{array}{l}\text { Masic flow rate } \\ m_{v}\end{array} \\ Z_{1} & \begin{array}{l}\text { mass of gas trapped in the working volume } \\ \text { the number of lobes of the leading rotor } \\ \text { the rotational speed of the rotor, rot/minute }\end{array} \\ \dot{V} & \text { Volumetric flow rate } \\ \dot{m}_{t} & \text { Theoretical mass flow rate } \\ A_{1 N} & \text { frontal area of the lobe } 1 \text { in a section } \\ A_{2 N} & \text { perpendicular to their axis } \\ & \text { frontal area of the lobe } 2 \text { in a section } \\ \mathrm{L} & \text { perpendicular to their axis } \\ P_{\text {ind }} & \text { length of the lobes } \\ \mathrm{p} & \text { indicated power } \\ \mathrm{t} & \text { Pressure, bar } \\ & \text { Temperature, }{ }^{\circ} \mathrm{C}\end{array}$

\section{Greek symbols}

$\begin{array}{ll}\rho_{0} & \text { Standard density, } \mathrm{kg} / \mathrm{Sm}^{3} \\ \rho_{N} & \text { Normal density, } \mathrm{kg} / \mathrm{Nm}^{3} \\ \eta_{V} & \text { Volumetric efficiency }\end{array}$

\section{Subscripts}

$\begin{array}{ll}1 & \text { Entry point } \\ 2 & \text { Exit point }\end{array}$

